\title{
17
}

\section{Teaching Through Discussion as the Exercise of Disciplinary Power}

\section{Stephen D. Brookfield}

University of St. Thomas

The French philosopher Michel Foucault spent much of his lifetime analyzing the way in which power flows through all human interactions, including those of discussion groups within higher education. His analysis of disciplinary power and surveillance is directly applicable to the practice of discussion-based teaching.

\section{INTRODUCTION}

Since 1998, one of the most frequent faculty development workshops I $S_{\text {have facilitated has been on discussion as a way of teaching. I usually }}$ describe this as a hands-on introduction to some basic discussion techniques designed to get students talking. During the course of the workshop, participants usually raise questions about whether or not it is ever justified to call on students by name, whether teachers should ever give their opinion in direct response to a student's query (thus biasing subsequent conversation), and whether teachers have a responsibility to guide discussion away from what they judge are irrelevant side issues. In talking about these issues, the phenomenon of power rears its head. Sooner or later we come to face to face with the undeniable power of the discussion leader, and we start to discuss the way in which it can be exercised responsibly. During this moment in the workshop, I usually mention Michel Foucault and that he saw power as a circular flow, rather than as something either imposed from above or emerging as part of a groundswell of resistance from below. If there is one name and one book I'd like participants 
think about reading after the workshop it would be Foucault and his collection titled Power/Knowledge (1980). Reading Foucault makes us more circumspect, but more critically informed, regarding the ways discussionbased teaching equalizes power relations in the classroom and promotes truly participatory learning.

This chapter explores the relevance of Foucault's analysis of power for the conduct of discussion and examines common practices of discussion for the power relations they exhibit. To many university and college teachers, power is a Janus-like phenomenon, presenting two contradictory and mutually exclusive faces-repressive and liberatory. Repressive power is to be avoided if at all possible since it constrains and coerces, bending its subjects to its will. Liberatory power, on the other hand, is to be commended, since it activates and engages students, helping people take control of their lives. In the Professional and Organizational Development Network (POD) circles, it is the liberatory face of power that animates much of what we do. Faculty developers talk emphatically of empowerment as a process through which teachers help learners find their voices and develop the self-confidence to take control of their lives. The empowering urge is shared both by teachers who place themselves in the liberal-humanist tradition, and by those who see themselves as critical pedagogues. Empowering students is what we're about as teachers, and empowering teachers to be creative risk-takers is what we're about as faculty developers.

\section{Foucault and Power}

A critique of the Janus-like dichotomy of power as being exercised for good or evil lies at the heart of the work of Michel Foucault, the French social theorist (Foucault, 1977, 1980, 1982). In his view, power is never unitary, and neither wholly good or wholly bad. Repression and liberation coexist to different degrees wherever power is present. Hence, "it would not be possible for power relations to exist without points of subordination which, by definition, are means of escape" (Foucault, 1982, p. 225). Foucault regards power as omnipresent, etched into the minutiae of our daily lives. We cannot avoid exercising the power that flows through a social situation, even when we claim to have left power at the door, as in a faculty retreat or departmental brainstorming session. Power moves around a room, whether this is an undergraduate class or departmental meeting. This is a decentralized view of the functioning of power that is in marked contrast to a view which sees power as possessed chiefly by a 
dominant elite, exercised from above and emanating from a central location that is clearly identifiable. To Foucault, "power reaches into the very grain of individuals, touches their bodies and inserts itself into their actions and attitudes, their discourses, learning processes and everyday lives" (1980, p. 39). Consequently, his study of power has concentrated on understanding its manifestation in everyday rituals and interactions. He studies power "at the extreme points of its exercise ... where it installs itself and produces real effects" (Foucault, 1980, p. 197). In faculty development, the extreme points of exercise are the configurations of specific practices-peer review, teaching journals, self-designed developmental contracts, team teaching, and so on-often promoted by faculty developers as representing best student-centered practices.

Anyone guided by the philosophy of empowering teachers (in my experience a majority of those who identify themselves as faculty developers working within the field) benefit from reading Foucault. The fact that his writing is sometimes difficult to follow means it is easy to give up, but the struggle to understand and apply him is worth it. Without an appreciation of Foucault's ideas, faculty developers often end up with an incomplete and naive understanding of how power manifests itself in college classrooms. His work is crucial in helping us learn to recognize the presence of power in our daily practices, particularly the false face of apparently beneficent power exercised to help teachers or learners realize their full potential. As faculty developers, we can never escape the contradictions of power, and it is dangerous to say we can ever be fully aware of exactly how power is flowing around our workshops, institutes, and training sessions. However, reading Foucault can bring us to a better understanding of some of the unanticipated consequences of our supposedly empowering practices.

\section{Disciplinary Power}

Foucault subsumed many of his most important ideas within a single concept, that of disciplinary power. Disciplinary power describes the processes by which we discipline ourselves to conform to an imagined ideal. For example, in a classroom discussion group, disciplinary power is exercised in practices such as the raising of hands to signify one wants to speak, the way eye contact is made between participants to signal to each other that they can speak, the preferred seating arrangement (usually a circle), and the form of speech and terminology that is approved. These things are rarely enshrined in some form of charter or formal class 
protocol. They are implicit, understood by participants as appropriate. In a professional development institute, disciplinary power might be seen in the way that junior faculty defer to senior faculty when the chance to contribute to a discussion occurs, or the way there's an unspoken agreement not to address anything too contentious.

Most people in the 20th century still think of power in sovereign terms; that is, as located in a clearly identifiable individual or political unit (the monarch, president, central committee of the party). Foucault believed this to be 200-300 years behind the times. In the 18th and 19th centuries, the economy of disciplinary power established "the circulation of effects of power through progressively finer channels, gaining access to individuals themselves, to their bodies, their gestures and all their daily actions" (Foucault, 1980, p. 152). Disciplinary power was in many ways more insidious, more sinister, than the workings of sovereign power, being based on "knowing the inside of people's minds" (Foucault, 1982, p. 214). At its heart were "procedures which allowed the effects of power to circulate in a manner at once continuous, uninterrupted, adopted and 'individualized' throughout the entire social body" (Foucault, 1980, p. 119). Disciplinary power exhibits an "attentive malevolence" (Foucault, 1977 , p. 139) and is "a type of power which is constantly exercised by means of surveillance" (Foucault, 1980, p. 104). It is seen most explicitly in the functioning of prisons, but its mechanisms are also at play in schools, factories, social service agencies, and higher education. This form of power turns lifelong learning into a lifelong nightmare of "hierarchical surveillance, continuous registration, perpetual assessment and classification" (Foucault, 1977, p. 220).

Disciplinary power exhibits spatial and temporal dimensions. Learners are separated into individual cubicles and study carrels, or behind individual computer terminals, working on individual projects. Professional examinations are taken, essays written, and graduate theses submitted, as individual acts of intellectual labor. The collective learning represented by three or four students writing an essay together as a collaborative project, or two or three professors coauthoring scholarly articles, is discouraged as a plagiaristic diversion of the intellectually weak. Disciplinary power also breaks down time by arranging learning in a sequence of discrete stages. Training and professional practice are detached from each other, the curriculum is divided into elements for which predetermined amounts of time are allocated, and the timetable becomes the pivotal reference point for the organization of learners' and educators' activities. 
A central mechanism of disciplinary power is the examination. The examination has "the triple function of showing whether the subject has reached the level required, of guaranteeing that each subject undergoes the same apprenticeship and of differentiating the abilities of each individual" (Foucault, 1977, p. 158). Those who go through a series of examinations have their lives fixed and recorded in documents. People are sorted, classified, and differentiated by the examination which functions as "a normalizing gaze, a surveillance that makes it possible to qualify, to classify and to punish" (Foucault, 1977, p. 184). When achievements and aptitudes are judged by exams then we enter "the age of examinatory justice" (Foucault, 1977, p. 305) in which "the judges of normality are present everywhere" (Foucault, 1977, p. 304).

\section{Disciplinary Power and the Discussion Circle}

Let us turn now to a consideration of the way disciplinary power is present in the smallest, apparently most inconsequential, human interactions. As we have seen, Foucault views power as something embedded in the everyday lives of citizens and in the everyday activities of learners and teachers. Power flows around the body politic and around the college classroom, rather than being located at one clearly discernible point. It is continually in use, always being renewed, altered, and challenged by all those individuals who exercise it. Foucault writes that "power is employed and exercised through a net-like organization. And not only do individuals circulate between its threads; they are always in the position of simultaneously undergoing and exercising this power... individuals are the vehicles of power" (Foucault, 1980, p. 98).

To Foucault, power relations are manifest in all higher education interactions; even those that seem the freest and most unconstrained. Students, just as much as teachers, are the vehicles of power. As an example, the circle is an educational practice that appears to equalize power relations, if not escape from them entirely. At POD conferences, it is almost compulsory for presenters (myself included) to arrive at the room early and move the chairs into a circle, space and content permitting. Whenever I have done this I assume I am demonstrating my commitment to honoring learners' voices and experiences, and to removing my own coercive power from the educational setting. To instructors who use discussion methods regularly in their own teaching, the circle is probably the room arrangement they instinctively prefer. 
For many years, the circle has been so sacred and reified in my own teaching that I took it as an unchallengeable sign of my democratic purity and learner-centeredness. However, following Foucault, it is quite possible that participants may regard the discussion circle as an oppressive experience, as a situation in which the possibility of surveillance is dramatically heightened. Usher and Edwards write that while putting chairs in a circle "may create different discursive possibilities, it nonetheless simply reconfigures the regulation of students. They may not be so directly subject to the teacher/lecturer but they remain under the immediate scrutiny and surveillance of their peers.... Changing practices do not, then, do away with power but displace it and reconfigure it in different ways" (1994, p. 91). In a circle students know that their lack of participation, or their poorly articulated contribution, will be all the more evident to their peers.

Gore (1993) builds on Foucault's work to argue that beneath the circle's democratic veneer there may exist a much more troubling and ambivalent reality. For learners who are confident, loquacious, and used to academic culture, the circle holds relatively few terrors. It is an experience that is congenial, authentic, and liberating. For students who are shy, aware of their different skin color, physical appearance, or form of dress, unused to intellectual discourse, intimidated by disciplinary jargon, and the culture of academe, or conscious of their accent or lack of vocabulary, the circle can be a painful and humiliating experience. These learners have been stripped of their right to privacy. They are denied the chance to check educators out by watching them closely before deciding whether or not they can be trusted. This trust only develops over time as teachers are seen to act consistently, honestly, and fairly. Yet the circle, with its implicit pressure to participate and perform, may preclude the time and opportunity for this trust to develop. As such, it is a prime example of how apparently democratic educational practices exhibit power relations just as much as those labeled as autocratic or overly didactic.

So where does Foucault leave those of us who like the circle? Is the logic of his argument that we should abandon the circle and go back to the serried rows of earlier years? To me, this is not an either/or question. I continue to use the circle in my own practice but I hope in a more critically informed way. Foucault's analysis makes me aware of the circle's oppressive potential and reminds me that I must continually research how students experience it. Now I explain to students as they take their seats that I know the circle does not remove power relations from the group and that I realize the circle is often perceived as an oppressive 
mandating of participation. Sometimes this leads me to make a nospeech policy whereby I tell students that they have the right not to speak and that I will not interpret their silence as indicating apathy, hostility, or mental inertia. It may seem strange to suggest that you launch a discussion by advocating silence, but my experience has been that this puts diffident or introverted students at their ease.

The following is an example from my own teaching of a typical declaration I make to students at the start of a discussion-based course. It is intended to express my tolerance of silence and to inform students that participation in class discussion is entirely voluntary and should never be used to curry favor with me. It acknowledges that being in a circle increases the student's feeling of being under surveillance from peers as well as the teacher, and attempts to circumvent the performance anxiety this induces.

I know that speaking in discussions is a nerve-wracking thing and that your fear of making public fools of yourselves can inhibit you to the point of nonparticipation. I, myself, feel very nervous as a discussion participant and spend a lot of my time carefully rehearsing my contributions so as not to look foolish when I finally speak. So please don't feel that you have to speak in order to gain my approval or to show me that you're a diligent student. It's quite acceptable to say nothing in the session, and there'll be no presumption of failure on your part. I don't equate silence with mental inertia. Obviously, I hope you will want to say something and speak up, but I don't want you to do this just for the sake of appearances. So let's be comfortable with a prolonged period of silence that might, or might not, be broken. When anyone feels like saying something, speak up.

I believe in the power of this kind of early declaration because I've seen how well it works. Students will often come up to me afterwards and say that by granting them public permission not to say anything I actually emboldened them to speak. By deliberately destroying the link between student speech and teacher approval the pressure on students to look smart in front of me-the performance anxiety that kills so much discussion participation-is much reduced. The autobiographical disclosure that as a discussion group participant I suffer from the same performance anxiety also seems to reassure students that my experience is not as far from theirs as they might imagine. 


\section{Foucault and Discussion-Based Teaching}

Many instructors either maintain that they have no power over others, or that they can choose when, and when not, to exercise it. Foucault views such confidence with amusement. He sketches out a theory of power as a circular flow that draws all into its currents. Choosing whether or not to exercise power is, in his eyes, an illusory choice. In reality, we are fated to exercise power. Using Foucault's analysis, it is revealing to examine common student-centered practices that are celebrated for their intent to avoid the exercise of power by involving all participants equally. We do not need Foucault to help us recognize the exercise of sovereign power in higher education. This is seen in the lecturer who treats a group of students as if they were ten-year olds, allowing few questions and no unauthorized interruptions. What Foucault helps us recognize is that another more subtle form of power-disciplinary power-is often present in practices that are usually thought of as democratic and participatory.

\section{Discussion}

One of the most democratic and participatory of all methods of teaching is that of discussion. Discussion is the methodological jewel in the crown of progressive-humanist education, designed to serve as an experimental laboratory for the learning of democratic habits. Yet, talking of the discussion method as if it were a single, integrated approach to facilitating learning that achieves broadly the same democratic consequences each time it is used is hopelessly naive and simplistic. Discussion is a problematic form of practice that is culturally situated. Its meaning and significance vary according to (amongst other things) the race, class, and gender of its participants, the institutional and cultural location of the speech acts that comprise discussion, and the ways in which the facilitator's behavior is interpreted. The purpose for which discussion is heldfor example, to check whether students have properly understood concepts reviewed in readings and lectures, or to engage in ideology critique as a way of unmasking dominant cultural values-always represents a political stance, an ideological agenda.

The criteria underlying the evaluation of what counts as good discussion also spring from a particular sociopolitical milieu and represent the values of those who have managed to lever themselves into positions as professional gatekeepers. Not surprisingly, these values often accord with the prevailing values of laissez-faire capitalism. In fact, many teachers adopt a more or less conscious metaphor of the free market toward 
their practice, believing that the less interaction by the teacher, the better and more authentically student-centered the discussion. But intellectual exchanges in discussion never occur on a level playing field. Those who bring the greatest cultural capital to discussion find that participating in this activity ensures that they accrue yet more capital. Even the language teachers use to describe the outcomes they desire for discussion-getting students to "own" a concept or "buy into" an idea-buttress capitalist ideology.

Discussion groups in colleges and universities are not limpid; tranquil eddies cut off from the river of social, cultural, and political life. They are contested arenas-whirlpools containing the contradictory crosscurrents of the struggles for material superiority and ideological legitimacy that exist in the world outside. From a Foucaultian point of view, power is omnipresent in discussion. The flow of power can be named and redirected, and its seat can shift around the group, but it can never be denied or erased. Becoming aware of how the dynamics of power permeate and move among discussion group members helps us realize that forces present in the wider society always intrude into the classroom. Patterns of participation and deference based on race, class, and gender, unless deliberately named and challenged, invariably reproduce themselves as the natural order of things in the discussion.

\section{Surveillance}

Surveillance is one of the relations of power that lends itself to discussion. In a discussion group, we cannot be unobserved by staying silent. Our very silence draws attention to us. We may be unheard but we will not be unnoticed. Surveillance is the most important component of disciplinary power. In a society subject to disciplinary power, we discipline ourselves by watching others and ourselves. There is no need for the state to spend enormous amounts of time and money making sure we behave correctly since we are watching ourselves to make sure we don't step out of line. What makes us watch ourselves so assiduously is not an internal resolve to follow normal ways of thinking and acting, thereby avoiding a fall into disgrace. Instead, we watch ourselves because we sense that our attempt to stay close to the norm is itself being watched by another, allseeing, presence. We carry within us the sense that "out there," in some hidden, undiscoverable location, "they" are constantly observing us. It is hard to deviate from the norm if you feel cameras hidden in every corner of your life are recording your thoughts and actions (figuratively and sometimes literally). 
For Foucault, "the perfect disciplinary apparatus would make it possible for a single gaze to see everything constantly" (1977, p. 173), and for those being surveyed to be aware that at any time they may be subject to invisible scrutiny. "It is the fact of constantly being seen, of being able always to be seen, that maintains the disciplined individual in all his subjection" (Foucault, 1977, p. 187). Few methods of teaching in higher education are so suited to surveillance as discussion, inviting as it does surveillance by peers as well as teachers. Participants know their every word is heard, their every move seen, by someone in the group. This may help people focus on the issue at hand, but it may equally well deny them the reflective, relaxed pose, the time to glaze over and let ideas cogitate, and the silence necessary to understand and make connections between complex ideas. The norm of alertness, of showing that you're engaged in the discussion by making eye contact, nodding, and uttering "uh-huh," disallows all these things.

\section{Discussion Leaders}

Discussion as a way of learning that is quintessentially student-centered can be experienced by learners as performance theater. Students are actors in a loosely improvised drama, the broad outlines of which are implicitly agreed on in advance. Their performance as discussion participants is carefully watched by "the judges of normality" (Foucault, 1977, p. 304). These judges (discussion leaders) monitor the extent to which participants are participating in the conversation in a suitable manner. Foucault argues that "the universal reign of the normative" (1977, p. 304)the standard prescription for how one should think and behave-means that each person "subjects to it his body, his gestures, his behavior, his aptitudes, his achievements” (1977, p. 304). Many discussion groups are certainly influenced by an unexpressed norm of what constitutes good discussion. This norm holds that such discussions are those in which everyone speaks intelligently and articulately for roughly equal amounts of time and all conversation is focused on the topic at hand. In this norm of the good discussion there is little silence. What conversation takes place focuses only on relevant issues with a suitably sophisticated level of discourse. Talk flows scintillatingly and seamlessly from topic to topic. Everyone listens attentively and respectfully to everyone else's contributions. People make their comments in a way that is informed, thoughtful, insightful, and unfailingly courteous. The Algonquin roundtable or Bloomsbury dinner parties are the exemplars the norm implies, and the one toward which participants direct their discussion performances. 
Discussion leaders as judges of normality overtly reinforce the power of this norm by establishing criteria for participation that operationalize the norm's rules of conduct. Assigning part of a grade for participation, without defining what participation means, activates the norm's influence over participants. Learners immediately interpret participation as doing their best to exemplify this norm. They carefully rehearse stunningly insightful contributions that will make them sound like Cornel West or Gertrude Stein. Discussion teachers also covertly reinforce this norm by their subtle deployment of nonverbal behaviors signifying approval or disapproval of participants' efforts to exemplify the norm. Through nods, frowns, eye contact (or the lack of it), sighs of frustration or pity, grunts of agreement, disbelieving intakes of breath at the obvious stupidity of a particular comment, and a wide range of other gestures, discussion leaders communicate to the group when they are close to, or moving away from, the norm. Unless discussion leaders redefine criteria for discussion participation to challenge this norm, students will work assiduously to gear their behavior toward its realization.

\section{The Unavoidable Exercising of Power: The Practice of Discussion Informed by Foucault}

I want to respond to the foregoing analysis by examining specific discussion practices and responsibilities, focusing particularly on the role of the teacher. As educators we cannot avoid taking action. The discussion leader cannot be a laissez-faire facilitator, exercising a minimum of control. Taking this stance only serves to allow patterns of inequity present in the wider society to reproduce themselves automatically in the classroom. Instead, the teacher must intervene to introduce a variety of practicessuch as the circle of voices, periods when only those who have not spoken are allowed to speak, the ground rule that we can only speak about others' ideas (not our own), and the circular response technique (Brookfield \& Preskill, 1999)-to ensure some sort of equity of participation.

Many teachers would like to believe either that they have no special power over students, or that any power mistakenly attributed to them by participants is an illusion that can quickly be dissolved by a refusal to dominate the group. But it is not that easy. No matter how much we protest our desire to be at one with learners there is a predictable flow of attention focused on us. While it is important to privilege learners' voices and to create multiple foci of attention in the classroom, it is disingenuous to pretend that as teachers we are the same as our learners. It is better 
to acknowledge publicly our position of power, to engage students in deconstructing that power, and to attempt to model a critical analysis of our own source of authority in front of them. This will sometimes involve us in becoming alert to, and publicly admitting, oppressive dimensions to practices that we had thought were neutral or even benevolent.

I know that I can never entirely escape the web of power relationships within which a discussion class operates. Structures of inequity existing outside the class frequently reproduce themselves within. I know, too, that a universal democratic purity of practice is an illusion, and that if I measure my work by whether or not I realize this I am doomed to perpetual guilt. But I know, too, that discussion groups can be more or less democratic, that the problematic nature of discussion can be continuously revealed, and that we can come to more informed and sophisticated understandings of how we are implicated in the unwitting maintenance of regimes of truth. The following are some of the steps I take to accomplish these ends. Others are described more fully in Brookfield and Preskill (1999).

Early in any discussion-based course, we can ensure that the group wrestle with creating what Bridges (1988) calls a moral culture for discourse-more prosaically, ground rules for conversation. These rules can be developed in several ways. The leader can suggest them, but that can seem a somewhat arbitrary exercise of teacher power. A better option is for students to generate these by reviewing their past autobiographical experiences as discussion participants to identify features they want to emphasize and avoid, and then generate specific procedures that encapsulate these preferences. Usually, these ground rules focus strongly on equalizing participation, guarding against behaviors such as hate speech, and preserving students' right to silence.

We can also make sure that the group's experience of discussion is constantly researched through a classroom assessment or action research approach such as the critical incident questionnaire (CIQ) (Brookfield, 1995 ) or discussion audit. In the CIQ students write a weekly anonymous commentary on their experience of discussion, which is compiled and reported back to the class. The security that this instrument's anonymity affords emboldens students to make explicit the inequities of participation they observe, the imbalances in voice they notice, possible discrepancies between the group's espoused rules of conduct and its actual behavior, and any arbitrary abuses of power by the teacher or other group members. In the weekly reporting out of the previous week's CIQ data, the problematic nature of power relationships in the 
group becomes a matter for public discussion. The group learns to delve deeper and deeper in understanding how power is exercised and resisted at the specific site of a discussion-based course.

Any attempt to democratize discussion invariably raises the question whether or not teachers should require all students to participate in discussion, or whether this is a return to old-style sovereign power. Mandating participation seems like a repressive act that stands in direct contrast to the spirit of democratic conversation. However, hooks (1994) argues forcibly that there are occasions when it is justifiable to exercise power in this way. She requires students to read out paragraphs from their journals in class so that none feel invisible or silenced. To her, this is a responsible exercise of teacher power. Always allowing students the option to pass in discussion circles means that those who are shy and introverted, or uncomfortable because they perceive themselves as members of a minority race, gender, or class, end up not contributing. The longer this pattern of nonparticipation persists, the harder it is to break. In truly Foucaultian fashion, what seems like an empathic, benign action by the leader-allowing students the right to silence-serves to reinforce existing differences in status and power. Those used to holding forth will automatically speak, while those whose voices are rarely heard, will stay mute. In passing on the right to speak they ensure their continuing silence.

\section{Note}

Portions of this paper draw on an analysis of Foucault that first appeared in the Canadian Journal for the Study of Adult Education, Vol. 15, No, 1, 2001.

\section{REFERENCES}

Bridges, D. (1988). Education, democracy, and discussion. Lanham, MD: University Press of America.

Brookfield, S. D. (1995). Becoming a critically reflective teacher. San Francisco, CA: Jossey-Bass.

Brookfield, S. D., \& Preskill, S. (1999). Discussion as a way of teaching: Tools and techniques for democratic classrooms. San Francisco, CA: Jossey-Bass.

Foucault, M. (1977). Discipline and punish: The birth of the prison. New York, NY: Vintage. 
Foucault, M. (1980). Power/knoweledge: Selected interviews and other writings, 19721977. New York, NY: Pantheon.

Foucault, M. (1982). The subject and power. In H. L. Dreyfus \& P. Rabinow (Eds.), Michel Foucault: Beyond structuralism and hermeneutics (pp. 214-225). Chicago, IL: University of Chicago Press.

Gore, J. (1993). The struggle for pedagogies: Critical and feminist discourses as regimes of truth. New York, NY: Routledge.

hooks, bell. (1994). Teaching to transgress: Education as the practice of freedom. New York, NY: Routledge.

Usher, R., \& Edwards, R. (1994). Postmodernism and education: Different voices, different worlds. London, England: Routledge.

Contact:

Stephen D. Brookfield

Mail \#MOH 217

School of Education

University of St. Thomas

$1000 \mathrm{LaS}$ alle Avenue

Minneapolis, MN 55403-2009

(651) $962-4982$

Email:sdbrookfield@stthomas.edu

Stephen Brookfield holds the title of Distinguished Professor at the University of St. Thomas. He is a three-time winner $(1986,1989$, and 1996) of the Cyril O. Houle World Award for Literature in Adult Education and currently serves on the editorial boards of adult education journals in the United States, Canada, England, and Australia. 